\begin{tabular}{|c|c|c|}
\hline \multirow{4}{*}{$\begin{array}{l}\text { ISSN: 1410-8917 } \\
\text { Jurnal Kimia } \\
\text { Aplikasi }\end{array}$} & Jurnal Kimia Sains dan Aplikasi 21 (2) (2018): 102-106 & \\
\hline & Jurnal Kimia Sains dan Aplikasi & \\
\hline & Journal of Scientific and Applied Chemistry & \\
\hline & Journal homepage: http://ejournal.undip.ac.id/index.php/ksa & \\
\hline
\end{tabular}

\title{
Effect of Acid on Natural Zeolite Dealumination on Indigo Carmine Adsorption Capability
}

\author{
Nanik Sulistyowati $^{\text {a }}$, Sriyanti ${ }^{\mathrm{a}^{*}}$, Adi Darmawan ${ }^{\mathrm{a}}$ \\ a Inorganic Chemistry Laboratory, Chemistry Department, Faculty of Sciences and Mathematics, Diponegoro University, Jalan Prof. \\ Soedarto, Tembalang, Semarang \\ * Corresponding author: sriyanti@live.undip.ac.id
}

\begin{tabular}{l}
\hline Article Info \\
\hline \\
\hline Keywords: \\
zeolite; \\
dealumination; \\
$\mathrm{H}_{2} \mathrm{SO}_{4} ; \mathrm{HCl} ;$ \\
adsorption; indigo \\
carmine
\end{tabular}

Kata Kunci: zeolit; dealuminasi; $\mathrm{H}_{2} \mathrm{SO}_{4} ; \mathrm{HCl}$; adsorpsi; indigo carmine

\begin{abstract}
Modifying natural zeolite with dealumination using $\mathrm{H}_{2} \mathrm{SO}_{4}$ and $\mathrm{HCl}$, and its application to adsorb indigo carmine has been performed. Dealumination was carried out by reacting a natural zeolite with a mixture of $\mathrm{KMnO}_{4}-\mathrm{H}_{2} \mathrm{SO}_{4}$ and a mixture of $\mathrm{KMnO}_{4}-\mathrm{HCl}$ then refluxed for 5 hours followed by washing with demineralized water until a neutral $\mathrm{pH}$ was obtained and dried for 12 hours at $80^{\circ} \mathrm{C}$. Dealuminated zeolites were then characterized by XRD, FTIR and Si/Al ratio measurements. Dealuminated zeolite was then used to adsorb indigo carmine in a batch-shaker system for $30 \mathrm{~min}$ with concentration variation XRD diffraction shows that natural zeolite and dealuminated zeolite contain modernit minerals. Dealumination increased the Si/Al ratio from 0.935 to 2.075 and 7.912 which meant that dealumination was successful. The indigo carmine adsorption result showed that zeolite adsorption capacity $\mathrm{II}>$ zeolite $\mathrm{I}>$ natural zeolite. FTIR data showed that there was no change of zeolite structure before and after adsorption
\end{abstract}

Abstrak

Memodifikasi zeolit alam dengan dealuminasi menggunakan $\mathrm{H}_{2} \mathrm{SO}_{4}$ dan $\mathrm{HCl}$, serta aplikasinya untuk mengadsorpsi indigo carmine telah dilakukan. Dealuminasi dilakukan dengan mereaksikan zeolit alam dengan campuran $\mathrm{KMnO}_{4}-\mathrm{H}_{2} \mathrm{SO}_{4}$ dan campuran $\mathrm{KMnO}_{4}-\mathrm{HCl}$ kemudian direfluks selama 5 jam dilanjutkan dengan pencucian dengan air demineralisasi hingga $\mathrm{pH}$ netral diperoleh dan dikeringkan selama 12 jam pada suhu $80^{\circ} \mathrm{C}$. Dealuminated zeolite kemudian dikarakterisasi dengan XRD, FTIR dan pengukuran rasio Si/Al. Dealuminated zeolite kemudian digunakan untuk mengadsorpsi indigo carmine pada sistem batch-shaker selama 30 menit dengan variasi konsentrasi. Difraktogram XRD menunjukkan bahwa zeolit alam dan dealuminated zeolit mengandung mineral modernit. Dealuminasi meningkatan rasio Si/Al dari 0,935 menjadi 2,075 dan 7,912 yang berarti bahwa dealuminasi berhasil dilakukan. Hasil adsorpsi indigo carmine menunjukkan bahwa kemampuan adsorpsi zeolit II > zeolit I > zeolit alam. Data FTIR menunjukkan bahwa tidak terjadi perubahan struktur zeolit sebelum dan setelah adsorpsi

\section{Pendahuluan}

Zeolit merupakan mineral aluminosilikat terhidrasi yang mengandung alkali/alkali tanah dalam kerangka 3 dimensi. Berdasar sifat fisika dan kimia zeolit yang unik, zeolit banyak dimanfaatkan sebagai penukar ion, adsorben, penyaring molekuler dan katalis [1]. Zeolit juga dikenal sebagai adsorben dengan kapasitas dan selektivitas adsorpsi tinggi, yaitu dapat memisahkan molekul berdasarkan ukuran, konfigurasi dan kepolarannya. Zeolit alam mempunyai rasio $\mathrm{Si} / \mathrm{Al}$ rendah, cenderung selektif terhadap senyawa polar [1]. Untuk meningkatkan daya adsorpsi dan daya tukar 
ionnya terhadap ion maupun senyawa tertentu perlu adanya modifikasi. Beberapa teknik modifikasi antara lain dehidrasi, pertukaran ion, kalsinasi, dealuminasi dan proses hidrotermal [2].

Dealuminasi merupakan suatu metode modifikasi zeolit melalui pengurangan Al di permukaan dan dari kerangka zeolit. Zeolit terdealuminasi mempunyai rasio Si/Al tinggi (10-100) dan bersifat organofilik hidrofobik. Afinitas terhadap air berkurang dan cenderung mengadsorpsi senyawa organik non polar yang terlarut di dalam air tersebut [1].

Zeolit hasil modifikasi mempunyai rasio Si/Al yang tinggi sehingga mempunyai struktur pori yang terbuka akibatnya luas permukaannya meningkat. Rasio Si/Al yang tinggi ini menyebabkan zeolit terdealuminasi mampu mengadsorpsi senyawa organik non polar di antaranya pati dalam limbah tapioka [3].

Menurut Ermawati [4], dealuminasi zeolit alam Wonosari dengan $\mathrm{HCl}$ optimum pada konsentrasi $6 \mathrm{~N}$. Filho dkk. [5] telah berhasil melakukan dealuminasi pada lempung dengan menambahkan campuran kalium permanganat dan asam sulfat serta campuran kalium permanganat, asam sulfat dan asam klorida pada lempung disertai pemanasan. Penambahan asam klorida setelah direfluks dengan campuran asam sulfat dan kalium permanganat menunjukkan penurunan kadar aluminium yang cukup tinggi dibandingkan dealuminasi dengan campuran asam sulfat dan kalium permanganat saja. Tetapi dealuminasi dengan campuran asam klorida dan kalium permanganat tidak dilakukan, sehingga perlu dilakukan pengkajian pengaruh penurunan kadar aluminium (dealuminasi) menggunakan campuran asam sulfat dan kalium permanganat serta campuran asam klorida dan kalium permanganat saja. Dengan kata lain perlu diketahui efektivitas $\mathrm{HCl}$ dan $\mathrm{H}_{2} \mathrm{SO}_{4}$ dalam proses dealuminasi dan aplikasinya sebagai adsorben indigo carmine.

Indigo carmine merupakan zat warna organik yang banyak digunakan sebagai pewarna jeans. Limbah cair indigo carmine dalam lingkungan sangat berbahaya bagi kesehatan manusia. Diharapkan zeolit hasil modifikasi mampu menyerap limbah indigo carmine.

\section{Metode Penelitian}

\section{Alat dan Bahan}

Alat-alat yang digunakan meliputi seperangkat alat gelas indikator $\mathrm{pH}$, satu set alat refluks, neraca analitik Mettler AT 200, shaker, XRD-6000 X-Ray Diffractometer Shimadzu, IR Shimadzu FTIR-8201PC, Spektroskopi Serapan atom (AAS) dan Spektrofotometer Uv-Vis. Bahan-bahan yang diperlukan meliputi zeolit alam Wonosari, $\mathrm{H}_{2} \mathrm{SO}_{4}$ p.a $6 \mathrm{M}$, $\mathrm{HCl}$ p.a $6 \mathrm{M}, \mathrm{KMnO}_{4}$ p.a $0,5, \mathrm{M}$ akuades dan Indigo Carmine

\section{Dealuminasi zeolit dengan $\mathrm{KMnO}_{4}$ dan $\mathrm{H}_{2} \mathrm{SO}_{4}$ atau $\mathrm{HCl}$}

Sebanyak $100 \mathrm{~g}$ zeolit direfluks ke dalam $\mathrm{H}_{2} \mathrm{SO}_{4}$ (untuk zeolit I) atau $\mathrm{HCl}$ (untuk zeolit II) $6 \mathrm{M}$ dan $\mathrm{KMnO}_{4}$ 0,5 M dengan perbandingan 100:100 $\mathrm{mL}$ selama 4 jam pada suhu $80^{\circ} \mathrm{C}$ sambil diaduk pelan. Zeolit hasil refluks dicuci dengan akuades sampai air bekas pencuciannya netral, lalu dikeringkan dalam oven pada suhu $80^{\circ} \mathrm{C}$ selama 12 jam.

\section{Karakterisasi Zeolit}

Adsorben zeolit alam dan zeolit terdealuminasi dikarakterisasi strukturnya dengan menggunakan XRD (X-ray Diffraction) dan Spektroskopi Inframerah, penentuan rasio $\mathrm{Si} / \mathrm{Al}$ dengan Spektroskopi Serapan Atom (AAS), dan penentuan kemampuan adsorpsi dengan Spektroskopi UV-Vis.

\section{Adsorpsi Indigo Carmine oleh Adsorben Zeolit Terdealuminasi}

Sebanyak $1 \mathrm{~g}$ zeolit terdealuminasi dilarutkan dalam $20 \mathrm{~mL}$ larutan indigo carmine dengan variasi konsentrasi 10, 20, 30, 50, 100, 150, 200, dan $250 \mathrm{mg} / \mathrm{L}$. Adsorpsi dilakukan dalam sistem batch-shaker selama 30 menit pada temperatur kamar. Larutan supernatan disaring dan diukur untuk uji kuantitatif dengan menggunakan spektroskopi UV-Vis.

\section{Hasil dan Pembahasan}

Pada penelitian ini telah dilakukan pengamatan untuk mengetahui kemampuan zeolit terdealuminasi untuk mengadsorpsi limbah cair indigo carmine. Tahapan penelitian meliputi proses dealuminasi dan adsorpsi.

Tahapan dealuminasi bertujuan untuk mengurangi kadar Al dari kerangka dan struktur zeolit. Proses dealuminasi yang dilakukan meliputi pemanasan pada $80^{\circ} \mathrm{C}$ dalam campuran $\mathrm{KMnO}_{4}-\mathrm{H}_{2} \mathrm{SO}_{4}$ dan dalam campuran $\mathrm{KMnO}_{4}-\mathrm{HCl}$. Penggunaan $\mathrm{KMnO}_{4}$ dalam medium asam berfungsi untuk membersihkan oksidaoksida logam yang terdapat dalam zeolit alam dengan cara mengoksidasinya. Selanjutnya proses pencucian setelah perendaman dengan asam bertujuan untuk menghilangkan ion $\mathrm{Al}^{3+}$, kation-kation logam yang teroksidasi dan $\mathrm{KMnO}_{4}$ sisa

Zeolit alam maupun zeolit terdealuminasi dikarakterisasi menggunakan XRD, SSA dan FTIR sedangkan untuk mengukur kemampuan adsorpsinya digunakan Spektrofotometer UV-Vis.

\section{X-Ray Diffraction (XRD)}

Analisis struktur zeolit dilakukan dengan menggunakan XRD-6000 X-Ray Diffractometer Shimadzu. Berdasarkan difraktogram hasil difraksi sinar $\mathrm{x}$ terhadap zeolit Wonosari, tidak terjadi perubahan struktur kristal penyusun pada sampel zeolit awal maupun zeolit terdealuminasi. Pada sampel zeolit alam dan zeolit terdealuminasi terdapat kandungan mordernit. Gambar 1 menunjukkan spektra XRD zeolit alam dan zeolit terdealuminasi, nampak nilai $2 \theta$ sebesar 25,58; 22,17; 27,66 dan harga $d$ sebesar 3,48; 4,00; 3,22 $\AA$. Spektra ini menunjukkan karakteristik puncakpuncak dari mordernit yang mirip dengan ASTM (American Society for Testing and Materials). 


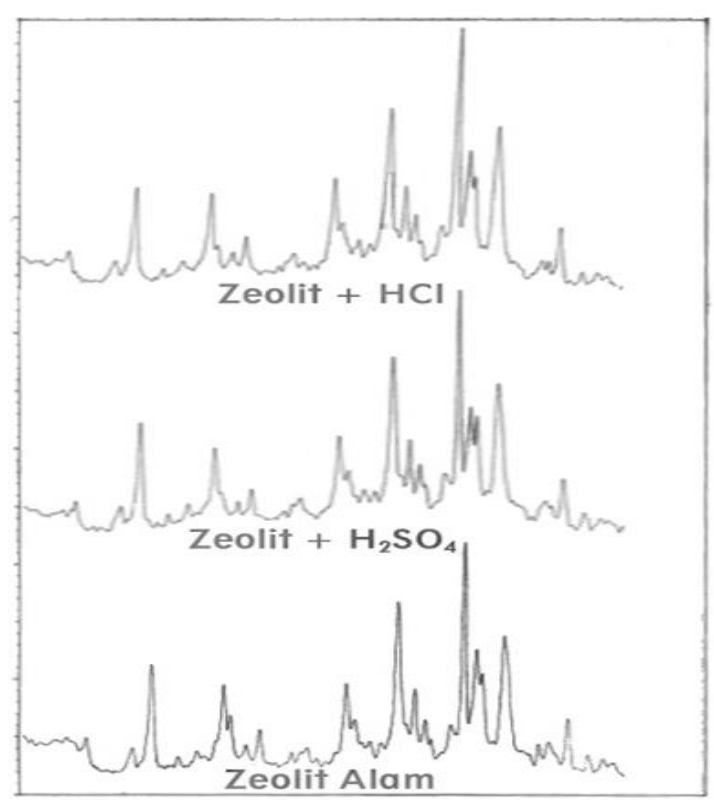

Gambar 1 Spektra zeolit alam dan zeolit modifikasi

Setelah membandingkan ketiga difraktogram dari zeolit alam dan zeolit terdealuminasi, ternyata ketiganya mempunyai difraktogram dengan harga $2 \theta\left(^{\circ}\right)$ dan harga $d(\AA)$ yang hampir sama, tetapi terdapat perbedaan intensitas. Hal ini berarti bahwa proses dealuminasi tidak merubah struktur kerangka zeolit hanya mengurangi kristalinitas dari zeolit.

Dari difraktogram terlihat adanya penurunan intensitas zeolit terdealuminasi, hal ini terjadi karena zeolit mengalami dekristalisasi sebagai akibat dari proses dealuminasi. Proses dealuminasi menyebabkan sejumlah atom Al keluar dari kerangka tetrahedral zeolit sehingga zeolit mengalami dekristalisasi pada satuan sel. Dekristalisasi akan mengakibatkan meningkatnya struktur kristal yang tidak homogen (lebih amorf) sehingga kristalinitasnya berkurang. Tabel 1 menunjukkan harga $d$ mordernit zeolit alam dan zeolit terdealuminasi yang diperbandingkan dengan ASTM.

Tabel 1 Harga $d$ mordernit dari zeolit alam, zeolit I, zeolit II dan ASTM

\begin{tabular}{cccccccc}
\hline \multicolumn{3}{c}{ Mordernit } & \multicolumn{2}{c}{ Zeolit alam } & \multicolumn{2}{c}{ Zeolit I } & \multicolumn{2}{c}{ Zeolit II } \\
\hline$d(\AA)$ & $\begin{array}{c}\mathrm{I} \\
(\%)\end{array}$ & $d(\AA)$ & $\begin{array}{c}\mathrm{I} \\
(\%)\end{array}$ & $d(\AA)$ & $\begin{array}{c}\mathrm{I} \\
(\%)\end{array}$ & $d(\AA)$ & $\begin{array}{c}\text { I } \\
(\%)\end{array}$ \\
\hline 9,100 & 90 & 9,131 & 47 & 9,15 & 39 & 9,132 & 47 \\
6,610 & 90 & 6,622 & 35 & 6,630 & 34 & 6,617 & 32 \\
4,530 & 80 & 4,539 & 36 & 4,541 & 36 & 4,537 & 34 \\
3,480 & 100 & 3,483 & 100 & 3,484 & 100 & 3,481 & 100 \\
3,390 & 90 & 3,399 & 47 & 3,399 & 46 & 3,400 & 43 \\
\hline
\end{tabular}

Berdasarkan harga $d$ di atas dapat disimpulkan bahwa kristalinitas zeolit I lebih besar dari zeolit II. Kristalinitas zeolit I yang tinggi mempunyai arti bahwa susunan kristal dari zeolit I lebih teratur dan homogen, karena Al yang hilang dari permukaan dan kerangka zeolit lebih sedikit. Sedangkan kristalinitas pada zeolit
II lebih rendah karena $\mathrm{Al}$ yang hilang selama proses dealuminasi lebih banyak, sehingga zeolit II mempunyai struktur yang lebih amorf dibandingkan seolit I. Hal ini diperkuat dengan data rasio Si/Al zeolit I yang lebih kecil daripada zeolit II, artinya lebih banyak Al yang hilang pada zeolit II daripada zeolit I.

\section{Rasio Si/Al}

Berdasarkan analisis data SSA (Spektroskopi Serapan Atom) diperoleh bahwa proses dealuminasi mampu meningkatkan rasio Si/Al dari 0,935 menjadi 2,075 untuk zeolit I dan 7,912 untuk zeolit II, yang ditunjukkan pada tabel 2. Meningkatnya rasio Si/Al zeolit mengindikasikan bahwa proses dealuminasi dengan asam telah berhasil dilakukan.

Tabel 2. Rasio Si/Al.

\begin{tabular}{cc}
\hline Jenis Zeolit & Rasio Si/Al \\
\hline Zeolit alam & 0,935 \\
Zeolit I & 2,075 \\
Zeolit II & 7,912 \\
\hline
\end{tabular}

Peningkatan rasio Si/Al disebabkan karena melarutnya sebagian aluminium di permukaan dan kerangka zeolit pada proses dealuminasi. Nilai energi ikatan Al-O adalah $116 \mathrm{kkal} / \mathrm{mol}$ dan energi ikatan Si-O adalah $184 \mathrm{kkal} / \mathrm{mol}$ [6], yang berarti bahwa ikatan AlO lebih lemah dibandingkan ikatan $\mathrm{Si}-\mathrm{O}$, sehingga ikatan $\mathrm{Al}-\mathrm{O}$ lebih mudah putus setelah bereaksi dengan asam.

Faktor lain yang menyebabkan meningkatnya nilai rasio $\mathrm{Si} / \mathrm{Al}$ adalah sifat $\mathrm{Al}$ yang lebih elektropositif dibandingkan $\mathrm{Si}$ (elektronegativitas Al adalah 1,5 sedangkan elektronegativitas Si adalah 1,8). Besarnya elektronegativitas mengindikasikan kemampuan suatu atom dalam bersaing mendapatkan elektron dengan atom lain yang berikatan. Semakin besar nilai elektronegativitasnya maka ikatan yang terbentuk akan semakin kuat [7]. Sehingga Al cenderung lebih mudah berikatan ketika ion $\mathrm{Cl}^{-}$atau $\mathrm{SO}_{4}{ }^{2-}$ menyerang $\mathrm{Al}$ yang bermuatan positif. Sementara Si yang cenderung netral lebih sulit untuk diserang oleh anion.

Besarnya rasio Si/Al juga dipengaruhi oleh kekuatan asamnya. Kekuatan asam $\mathrm{HCl}$ lebih besar dari $\mathrm{H}_{2} \mathrm{SO}_{4}$, hal ini dapat dilihat dari tetapan dissosiasinya $\left(\mathrm{Ka} \mathrm{HCl}=10^{7}\right.$ sedangkan $\mathrm{Ka}_{2} \mathrm{SO}_{4}=10^{2}$ ). Semakin besar harga $\mathrm{Ka}$ maka semakin mudah untuk terdisosiasi, sehingga kemampuan $\mathrm{Cl}^{-}$untuk berikatan dengan $\mathrm{Al}^{3+}$ lebih besar dari $\mathrm{SO}_{4}{ }^{2-}$. Menurut Perry dan Green [6] energi ikatan $\mathrm{Al}-\mathrm{Cl}$ adalah $119 \mathrm{kkal} / \mathrm{mol}$ sedangkan energi ikatan $\mathrm{Al}-$ $\mathrm{SO}_{4}$ adalah $79 \mathrm{kkal} / \mathrm{mol}$, ini berarti bahwa ikatan yang terbentuk antara $\mathrm{Al}-\mathrm{Cl}$ lebih kuat dibandingkan dengan ikatan antara $\mathrm{Al}-\mathrm{SO}_{4}$.

$\mathrm{H}_{2} \mathrm{SO}_{4}$ merupakan asam berbasa dua, hal ini berarti bahwa $\mathrm{H}_{2} \mathrm{SO}_{4}$ mengalami dua kali dissosiasi dan dua harga pKa. Harga $\mathrm{K}_{1}$ selalu lebih besar dari $\mathrm{K}_{2}$, artinya bahwa tingkat dissosiasi yang pertama selalu lebih sempurna daripada yang kedua, sehingga jumlah ion $\mathrm{SO}_{4}{ }^{2-}$ yang disumbangkan untuk berikatan dengan $\mathrm{Al}$ 
juga berkurang. Akibatnya $\mathrm{Al}$ yang berkurang dari proses dealuminasi hanya sedikit.

Menurut prinsip HSAB, asam keras cenderung untuk berikatan dengan basa keras dan asam lunak cenderung berikatan dengan basa lunak [8]. $\mathrm{Al}^{3+}$ merupakan asam keras karena mempunyai ukuran atom yang kecil dan muatan ion yang besar, sehingga jika bergabung dengan anion kecil muatan tinggi (basa keras) bentuk padatan yang dihasilkan mempunyai energi kisi yang tinggi. Sehingga $\mathrm{Al}^{3+}$ lebih senang untuk berikatan dengan ion $\mathrm{Cl}^{-}$dibandingkan dengan ion $\mathrm{SO}_{4}{ }^{2-}$ dikarenakan ukurannya yang kecil.

\section{Analisis spektra IR zeolit}

Menurut Hamdan [9], zeolit mempunyai vibrasi rentang asimetrik pada daerah $1250-900 \mathrm{~cm}^{-1}$, yang merupakan asosiasi dari rentangan $\mathrm{O}-\mathrm{Al}-\mathrm{O}$ dan $\mathrm{O}-\mathrm{Si}-$ O. Daerah rentangan simetrik muncul pada 680-850 $\mathrm{cm}^{-1}$ yang menunjukkan rentangan simetrik dari $\mathrm{O}-\mathrm{Si}-$ $\mathrm{O}$ atau $\mathrm{O}-\mathrm{Al}-\mathrm{O}$, di mana vibrasi eksternal muncul pada daerah 700-780 $\mathrm{cm}^{-1}$ dengan serapan cukup lemah. Hal ini diperkuat dengan serapan pada bilangan gelombang $420-500 \mathrm{~cm}^{-1}$, yang menunjukkan adanya vibrasi tekuk dari $\mathrm{Si}-\mathrm{O}$ atau $\mathrm{Al}-\mathrm{O}$.

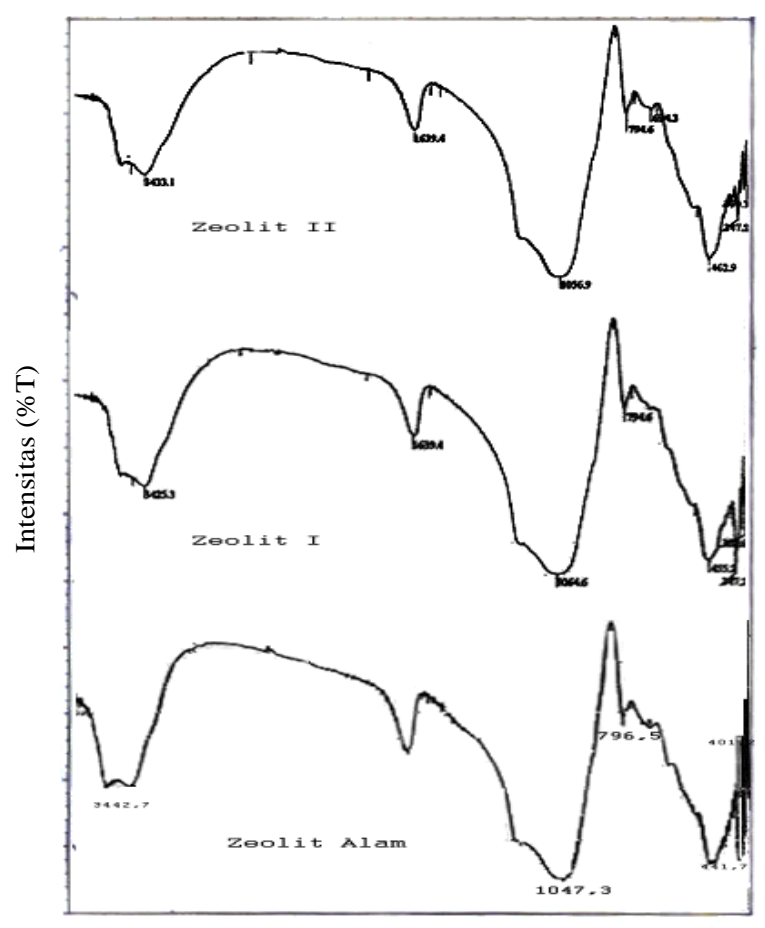

Bilangan gelombang $(1 / \mathrm{cm})$

Gambar 2 Spektra FTIR dari zeolit alam dan zeolit terdealuminasi

Gambar 2 menunjukkan spektra dari zeolit alam dan zeolit terdealuminasi. Pada spektra zeolit alam terlihat adanya gugus $\mathrm{O}-\mathrm{Si}-\mathrm{O}$ dan $\mathrm{O}-\mathrm{Al}-\mathrm{O}$, serapan kuat pada bilangan gelombang $1047,3 \mathrm{~cm}^{-1}$ yang diperkuat oleh serapan pada 796,5 $\mathrm{cm}^{-1}$. Rentangan asimetrik $\mathrm{O}-\mathrm{Si}-\mathrm{O}$ yang diperkuat oleh serapan vibrasi tekuk dari Si-O dan Al-O pada 401,2 $\mathrm{cm}^{-1}$ dan 441,7 $\mathrm{cm}^{-}$ ${ }^{1}$. Serapan-serapan di atas $1300 \mathrm{~cm}^{-1}$ bukan merupakan serapan karakteristik dari zeolit. Serapan pada 1637,5 $\mathrm{cm}^{-1}$ kemungkinan merupakan vibrasi rentangan $\mathrm{C}=\mathrm{O}$ dan serapan pada $3442,7 \mathrm{~cm}^{-1}$ menunjukkan adanyan vibrasi rentangan $\mathrm{OH}$.

Pada zeolit I terlihat adanya pergeseran bilangan gelombang untuk vibrasi $\mathrm{O}-\mathrm{Si}-\mathrm{O}$ dan $\mathrm{O}-\mathrm{Al}-\mathrm{O}$ dari $1047,3 \mathrm{~cm}^{-1}$ menjadi $1064,6 \mathrm{~cm}^{-1}$, hal ini menunjukkan bahwa telah terjadi dealuminasi. Menurut Cejka $d k k$. [10], dealuminasi pada mordernit secara spektroskopis dapat diamati pada daerah bilangan gelombang 300$1300 \mathrm{~cm}^{-1}$ berupa pergeseran puncak spektra yang berkaitan dengan vibrasi $\mathrm{Al}-\mathrm{O}$ dari $1055 \mathrm{~cm}^{-1}$ untuk mordernit alam menjadi $1095 \mathrm{~cm}^{-1}$ setelah pemanasan dalam 9,4 M HCl selam 18 jam.

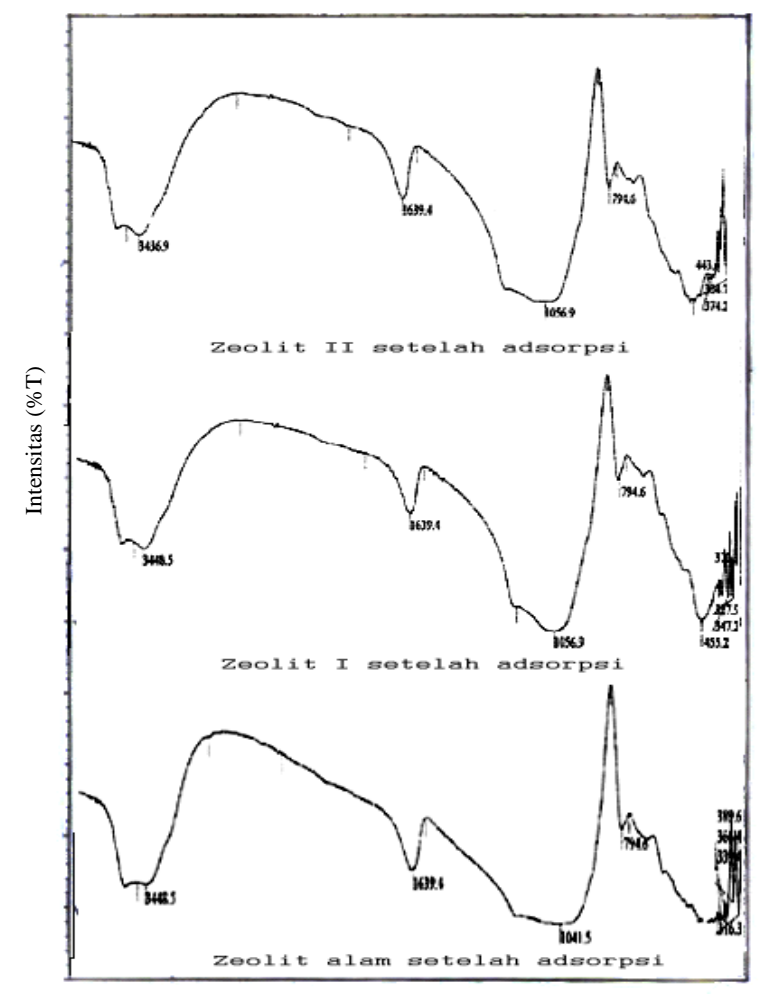

Bilangan gelombang $(1 / \mathrm{cm})$

Gambar 3 Spektra FTIR dari zeolit alam dan zeolit terdealuminasi setelah adsorpsi

Pada Gambar 3 spektra inframerah dari zeolit alam dan zeolit terdealuminasi setelah adsorpsi tidak mengalami perubahan pada pola spektranya. Puncakpuncak yang merupakan karakteristik dari zeolit alam dan zeolit terdealuminasi masih muncul kuat pada spektra ini. Sehingga dapat disimpulkan bahwa adsorpsi antara zeolit dengan indigo carmine merupakan adsorpsi fisik, karena struktur zeolit setelah adsorpsi tidak mengalami perubahan. Ini berarti bahwa indigo carmine tidak berikatan dengan zeolit.

\section{Adsorpsi Indigo Carmine}

Zeolit dengan rasio Si/Al tinggi memperlihatkan kecenderungan sifat yang hidrofobik. Hal ini ditunjukkan dengan adanya peningkatan kemampuan adsorpsi indigo carmine oleh zeolit terdealuminasi yang diperlihatkan pada Gambar 4. 


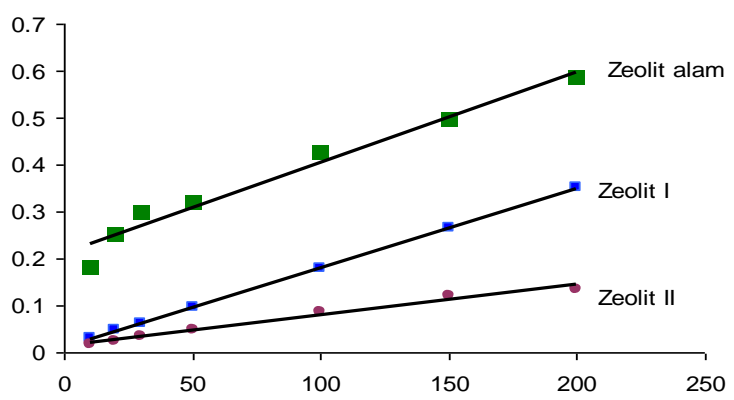

Gambar 4 Absorbansi indigo carmine oleh zeolit

Dari gambar 4 terlihat bahwa absorbansi zeolit II terhadap indigo carmine dengan variasi konsentrasi indigo carmine pada panjang gelombang $610 \mathrm{~nm}$ lebih rendah dari zeolit I, hal ini berarti bahwa zeolit II lebih banyak menyerap indigo carmine. Sehingga dapat disimpulkan bahwa zeolit II mempunyai kemampuan sebagai adsorben yang lebih baik daripada zeolit I.

Faktor yang mempengaruhi kemampuan adsorpsi zeolit adalah polaritas yang rendah dari zeolit terdealuminasi, yang ditunjukkan dengan meningkatnya rasio Si/Al. Faktor lain yang juga berpengaruh adalah adanya gugus-gugus aktif $\left(\mathrm{OH}^{-}\right)$di permukaan zeolit yang teraktifkan karena proses dealuminasi.

Proses adsorpsi antara zeolit dengan indigo carmine merupakan adsorpsi fisik. Hal ini didukung oleh spektra IR zeolit bahwa setelah adsorpsi zeolit tidak mengalami perubahan struktur, yang berarti indigo carmine tidak berikatan dengan zeolit. Adsorpsi fisik terjadi karena adanya interaksi gaya molekuler yang bersifat reversibel, sehingga semua adsorbat dapat dilepas kembali dengan menurunkan tekanan. Jadi dapat disimpulkan bahwa interaksi antara indigo carmine dengan zeolit adalah dengan cara menempel atau masuk kedalam pori zeolit.

\section{Kesimpulan}

Proses dealuminasi zeolit alam menggunakan campuran $\mathrm{HCl}-\mathrm{KMnO}_{4}$ dan $\mathrm{H}_{2} \mathrm{SO}_{4}-\mathrm{KMnO}_{4}$ telah berhasil dilakukan. Proses dealuminasi memberikan peningkatan rasio $\mathrm{Si} / \mathrm{Al}$, tetapi tidak merubah struktur kristal zeolit. Campuran $\mathrm{HCl}-\mathrm{KMnO}_{4}$ memberikan rasio $\mathrm{Si} / \mathrm{Al}$ yang lebih tinggi daripada campuran $\mathrm{H}_{2} \mathrm{SO}_{4}-$ $\mathrm{KMnO}_{4}$. Zeolit hasil dealuminasi menggunakan campuran $\mathrm{HCl}-\mathrm{KMnO}_{4}$ lebih bersifat hidrofobik dan merupakan adsorben indigo carmine yang lebih baik dari zeolit alam dan zeolit hasil dealuminasi menggunakan campuran $\mathrm{H}_{2} \mathrm{SO}_{4}-\mathrm{KMnO}_{4}$.

\section{Daftar Pustaka}

[1] Mursi Sutarti, Minta Rachmawati, Zeolit: Tinjauan Literatur, Pusat Dokumentasi dan Informasi Ilmiah, Lembaga Ilmu Pengetahuan Indonesia, Jakarta, 1994 .

[2] Fernando Ramôa Ribeiro, Zeolites: Science and Technology, Springer Netherlands, Netherlands, 1984 .
[3] Arnelli Arnelli, Thonang Arthono, Modifikasi Zeolit Alam untuk Adsorben, Jurnal Kimia Sains dan Aplikasi, 5, $1, \quad$ (2002) 8-11 http://dx.doi.org/10.14710/jksa.5.1.8-11

[4] Y. Ermawati, Pengaruh konsentrasi $\mathrm{HCl}$ dan $\mathrm{NH}_{4} \mathrm{NO}_{3}$ terhadap Dealuminasi Zeolit Alam Wonosari, Jurusan Kimia, Universitas Diponegoro, Semarang

[5] Newton L. Dias Filho, Yoshitaka Gushikem, Wagner L. Polito, 2-Mercaptobenzothiazole clay as matrix for sorption and preconcentration of some heavy metals from aqueous solution, Analytica Chimica Acta, $\quad 306, \quad 1, \quad$ (1995) 167-172 http://dx.doi.org/10.1016/0003-2670(94)00673-A

[6] Robert H Perry, Don W Green, Perry's chemical engineers' handbook, McGraw-Hill Professional, 1999.

[7] Ralph H Petrucci, Kimia Dasar Prinsip dan Terapan Modern, Penerbit Erlangga, Jakarta, 1985.

[8] Frank Albert Cotton, Geoffrey Wilkinson, Advanced Inorganic Chemistry, John Wiley \& Sons, Incorporated, 1988.

[9] Halimaton Hamdan, Introduction to Zeolites: Synthesis, Characterization, and Modification, Universiti Teknologi Malaysia, Kualalumpur, 1992.

[10] Jiri Cejka, Herman van Bekkum, A. Corma, F. Schueth, Introduction to Zeolite Molecular Sieves, Elsevier Science, 2007. 